\title{
Prediction on Crack Width based on ANSYS Nonlinear Analysis Wei-Ping ZHAO ${ }^{a^{*}}$, Hang GONG ${ }^{b}$, Ya-Zheng WANG ${ }^{c}$, Yun-Long XIE \\ China University of Mining \& Technology, Beijing, China

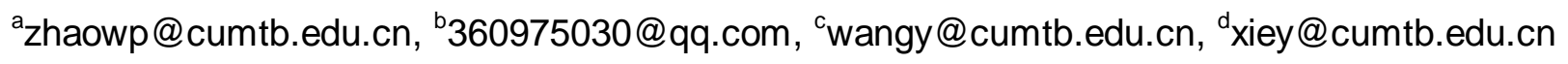 \\ ${ }^{*}$ Corresponding author
}

Keywords: Concrete Structure, Crack Width, Bond-slip, Non-linear, ANSYS.

\begin{abstract}
With the development of infrastructure, the problem of cracks in concrete structures is getting more and attention. Cracks will not only affect the appearance of the structure, if the cracks width are too large, even they can pose a threat for the durability and safety of structures, therefore we need to develop specific norms to control the width of the cracks. But in and abroad for the calculation of crack width is mainly empirical formula was obtained through a large number of experimental data, because of the differences of basic theory and experimental conditions, the empirical formula obtained vary widely, so that there is large gap on the results of cracks width. In this paper, combining reinforced concrete bond-slip theory with nonlinear simulation capabilities of ANSYS, we get the practical calculation method of concrete crack width, and the results were compared with experiment.
\end{abstract}

\section{Introduction}

Lots of research and practice have proved that the cracking of RC structure would be inevitable; cracks will affect the structure durability, aesthetics and function of normal use, and may even reduce the bearing capacity of the structure. The calculation results have certain discrete, and its research work still needed to be further explored.

$\mathrm{Lu}[1]$, etc. introduced the modeling method about using SOLID65 element to simulate concrete and steel fiber. All of these are of great significance and are adopted by numerous scholars [2, 3]. Based on ANSYS nonlinear analysis, this paper has proposed a new method to calculate the crack width of beams.

\section{Three-point Loading Experiment}

Full-scaled beam specimen was prepared (Fig1). Loading program of the specimen is applying vertical concentrated loads on the two three average points of the specimen. It means that the beam will form part of pure bending section in the middle of the span. The beam will formed part of pure bending section in the middle of the span. The development of cracks is more regular, and the data is more easily available. In addition, it also helps to use finite element simulation to establish matching model.

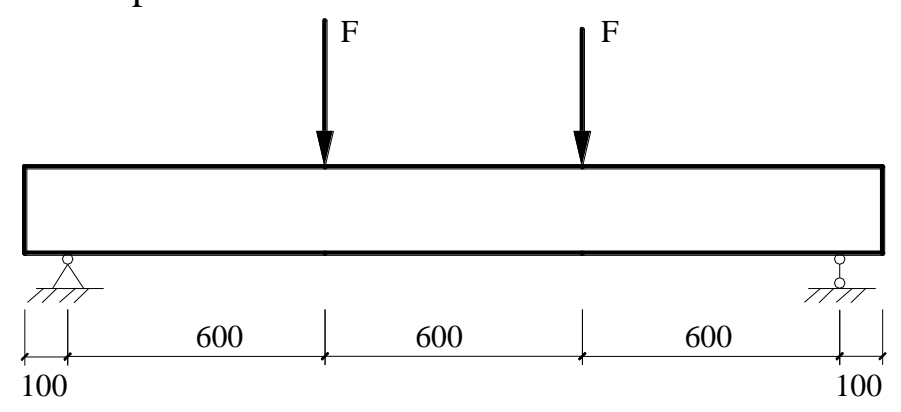

Fig. 1 Schematic Drawing of Loading Program

The loading system was set with 10 load steps: $5 \mathrm{kN}, 10 \mathrm{kN}, 15 \mathrm{kN}, 20 \mathrm{kN}, 25 \mathrm{kN}, 30 \mathrm{kN}, 35 \mathrm{kN}, 40 \mathrm{kN}$, $45 \mathrm{kN}, 48 \mathrm{kN}$. During the loading process, we should record three crack widths caused by each load. Crack detector was adapted to measure the crack width (Fig. 2). 


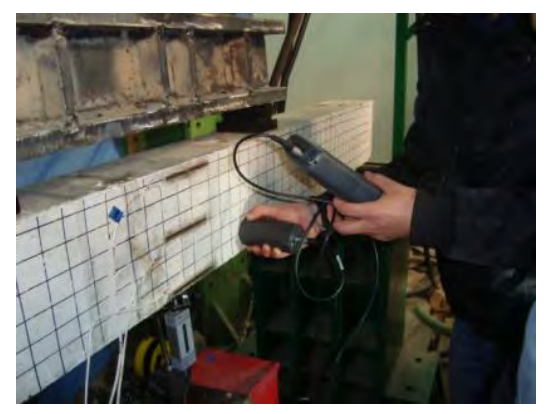

Fig. 2 Measurement of the Cracks

With the load gradually increasing, the crack width was recorded by the detector (Table1).

Tab. 1 Crack Width

\begin{tabular}{c|c|c|c|c}
\hline Load $(\mathrm{kN})$ & Crack 1(mm) & Crack 2(mm) & Crack 3(mm) & Average $(\mathrm{mm})$ \\
\hline 20 & 0.015 & 0.013 & 0.011 & 0.013 \\
\hline 25 & 0.021 & 0.019 & 0.023 & 0.021 \\
\hline 30 & 0.029 & 0.033 & 0.038 & 0.033 \\
\hline 35 & 0.070 & 0.062 & 0.080 & 0.071 \\
\hline 40 & 0.174 & 0.127 & 0.133 & 0.144 \\
\hline 45 & 0.188 & 0.135 & 0.162 & 0.161 \\
\hline 48 & 2.193 & 1.995 & 2.326 & 2.171 \\
\hline
\end{tabular}

\section{FEM Numerical Simulation}

With the help of former researcher [4-5], the FEM model was built (Fig.3 and Fig.4).

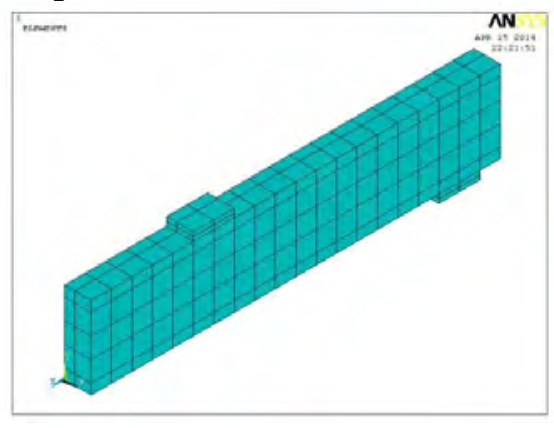

Fig. 3 Meshing of Concrete (1/4 model)

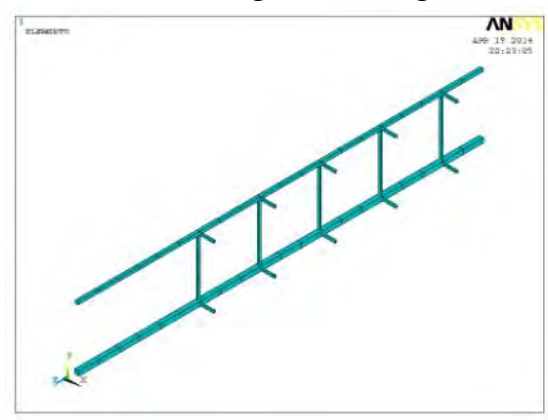

Fig. 4 Meshing of Steel Bar (1/4 model)

At last, bond-slip element COMBIN39 is generated between concrete and rebar (Fig. 5). D-F curve of element on the tangential directioncan be obtained from bond-slip constitutive relationship proposed by Mirza and Houde [6] (Fig. 6).

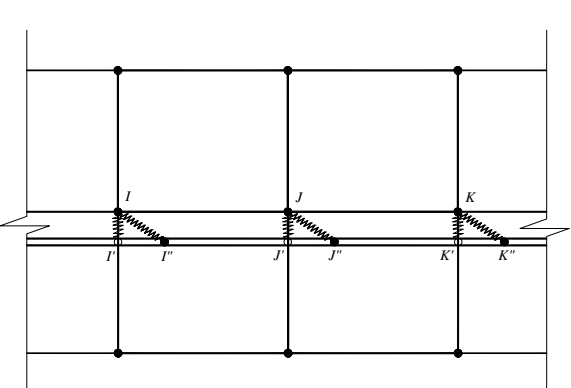

Fig. 5 Schematic Drawing of Use about COMBIN39

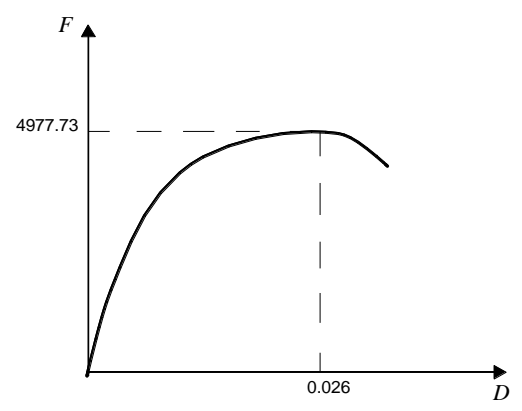

Fig. 6 Bond-slip Relationship

Comparison of the test and FEM was shown in Fig. 7, and the following conclusions can be drowned: 
1. Before reaching the steel bar yield, the simulation of the development of the crack width are in agreement with the test.

2. When the load is small, the difference between the FEM and test is relatively small. But when the load reaches $45 \mathrm{kN}$, namely the steel came to yield, the error between FEM and test are more obvious.

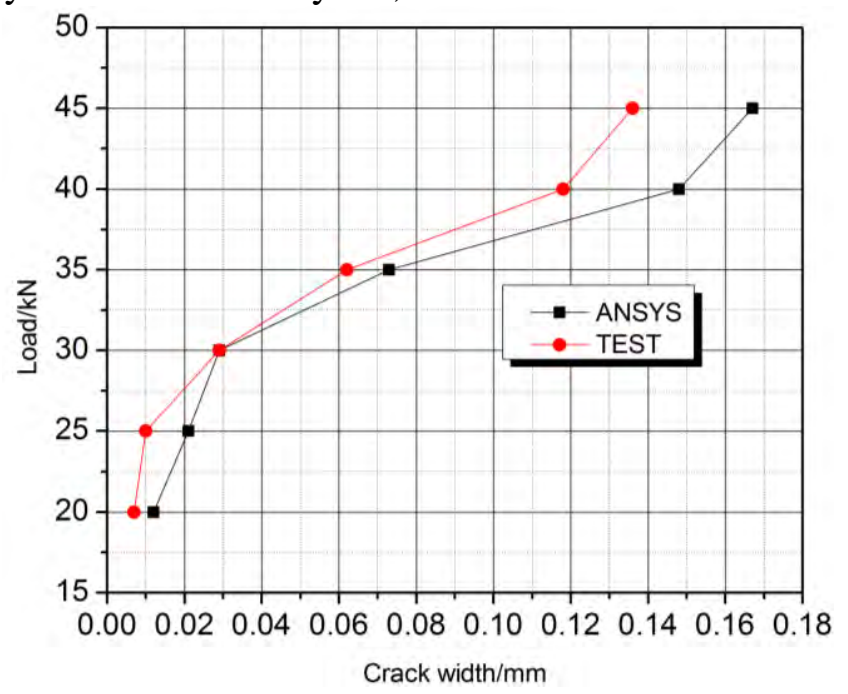

Fig. 7 Comparison of the Test and FEM

\section{Summary}

This paper has carried out of 3 point bending test of RC beams. With the advantage of finite element software ANSYS, a practical method for calculating the crack width are proposed. A comparison with experimental result indicated that the proposed method has a reasonable accurate before the bar yield. The error between FEM and test enlarged with increasing load, and the proposed method is not suitable for engineering application when steel bars have been yielded.

\section{Acknowledgement}

This research was financially supported by the National Science Foundation.

\section{References}

[1]LIN Jie, CHEN Hai-long, etc.. Nonlinear Finite Element Analysis of Reinforced Concrete Structure Based on Folium Crack Element [J]. Journal of Shi Jia Zhuang Railway Institute, 2007, 20, (1): 19-22.

[2]Reinhardt H W, Blaauwendraad J, Vose. Prediction of Bond Between Steel and Concrete by Numerical Analysis [J]. Materials and Structures, 1984, 17(4): 310-320.

[3]WANG Yi-qun,WANG Fu-zhi. Simulation of Bond -Slip Relation Between Concrete and Reinforcing Bar in ANSYS [J]. Journal of Tianjin University, 2006, 39(2): 210-213.

[4]GUO Zhen-hai. Principle and Analysis of Reinforced Concrete[M].Qing Hua University Press, 2003.

[5]JIANG Jian-jing. Nonlinear Finite Element Analysis for Reinforced Concrete [M]. Shan Xi Science and Technology Publishing House, 2002.

[6]Saeed M. Mirza and Jules Houde. Study of Bond Stress-Slip Relationships in Reinforced Concrete [J]. ACI J. Proc., 1979, 76(1): 19-46. 